\section{Undergraduate Research and Student Success Outcomes}

\section{doi: $10.18833 /$ spur/1/3/11}

I $\mathrm{n}$ the undergraduate research community, we make big and bold claims about the impact of undergraduate research on student success outcomes. Undergraduate research programs are built at the department, college, and university levels with the intention of moving the needle on student retention, grade point averages (GPAs), graduation rates, matriculation to graduate school, and student learning outcomes. Does undergraduate research deliver on our claims? How do we develop assessment plans to measure the impact of undergraduate research on specific student success outcomes? What is the appropriate mix of indirect and direct assessment measures? The articles and vignettes in the spring 2018 issue of SPUR not only help to answer these questions but also demonstrate the powerful impact of undergraduate research on student success outcomes.

In the assessment section, Laura Pawlow and Kristen Sleeper describe five assessment strategies used to evaluate the effectiveness of the Undergraduate Research and Creative Activities program at Southern Illinois University Edwardsville. They examine big-picture and nuts-and-bolts issues (What are students learning? What are barriers to participation? Are students aware of the program?), discussing benefits and challenges, as well as explaining how the quantitative and qualitative data have shaped the program.

Paulette Vincent-Ruz, Joseph Grabowski, and Christian D. Schunn examine an undergraduate research experience offered to first-year students at the University of Pittsburgh that shows a positive effect on retention rates, grade point averages, and admission to medical school even when controlling for race, gender, and SAT scores.

Andrea J. Sell, Angela Naginey, and Cathy Alexander Stanton explore the question of whether research involvement by undergraduates predicts subsequent academic success, as measured by GPA. Through a series of multiple regression analyses, their study of data gathered at California Lutheran University demonstrates that research involvement is associated with higher undergraduate GPA and also has implications for the scheduling of undergraduate research experiences during the individual's college career.
Stephanie L. Foster and Bethany M. Usher discuss George Mason University's locally developed assessment survey instrument in which students self-report on learning outcomes, attitudes, goals, personal and professional growth, and satisfaction items. Results from the individually mentored Undergraduate Research Scholars Program (URSP) and capstone-style research courses for seniors were compared. Although both groups reported highly positive attitudes and experiences overall, URSP students reported significantly more positive attitudes about doing research, more personal and professional development, and dramatically higher rates of learning on several inquiry outcomes.

The assessment section wraps up with Michelle Samura's analysis of the one-year capstone experience for the Integrated Educational Studies major at Chapman University. The capstone experience focuses on community engagement and inquiry-based learning. Qualitative assessment results highlight the positive impact of the capstone experience on the academic, professional, personal, and social development of students.

In the practice section, Catherine W. M. Chan, Prajukti Bhattacharyya, and Seth Meisel examine the Research Apprenticeship Program (RAP) at the University of Wisconsin-Whitewater, in which beginning students paired with mentors serve as paid research apprentices for one academic year. Preliminary data from the program indicate that both students and mentors value the program, and second- and third-year retention rates for RAP participants are higher than campus retention rates with a particularly powerful influence on first-generation and underrepresented minority students.

Thomas B. Higgins, Bernhard Beck-Winchatz, Michael Davis, and Andrew Kruger describe an undergraduate research program at the City Colleges of Chicago in highaltitude ballooning, which is conducted primarily in an open, maker-space environment. Their analysis of data from two student cohorts reveals a positive influence of the program on the involvement of community college students in research, student retention and college completion, and formation of scientific professional identity.

In another practice article, Michael S. Springer and colleagues discuss efforts to broaden participation in undergraduate research at the University of Central Oklahoma through an Office of High-Impact Practices, with particular attention to increasing research involvement of students in the College of Liberal Arts and College of Fine Arts and Design. 
The vignettes in this issue also provide valuable insights into the effect of undergraduate research on student outcomes. Laura Pawlow and Elizabeth J. Meinz compare data on undergraduate psychology research assistants (RAs) and those who did not serve as research assistants (non-RAs) at Southern Illinois University Edwardsville, finding that RAs significantly outperformed non-RAs in areas such as critical thinking, research methods, writing, and knowledge from required core courses, but the gains from the pretest to posttest for RAs and non-RAs were the same. Jacob Alan English and Christina Wan describe the synergies of an undergraduate research experience, development of cultural competence, and student success at Georgia State University. Frances Shen and colleagues explore the development of an undergraduate research certificate program at the University of Illinois Springfield that seeks to encourage academically underprepared students to engage in undergraduate research, provides training and support services, and assists in building student confidence and skills. Elizabeth Easley and Sarah Hunt Sellhorst discuss the establishment of a research club at the two-year, commuter-based University of South Carolina Lancaster that has contributed substantially to a culture of scholarly research among at-risk and first-generation students as well as faculty members. Regina Sullivan, Raji Subramaniam, and Patricia Schneider describe an effort at Queensborough Community College-CUNY that addresses STEM student retention, seeking to build student confidence in conducting and presenting research.

The ability to demonstrate the connections between undergraduate research programs and student success outcomes can be the key to administrative support, funding, and the institutionalization of such programs. The articles and vignettes in this issue provide ammunition to make the case and marshal the evidence for those critical connections. 